\title{
Diffuse Large B-Cell Lymphoma during Complete Remission of Acute Myeloid Leukemia (M4Eo) Exhibiting Immunoglobulin Heavy Chain Gene Rearrangement and Inv(16)
}

\author{
Kodai Kuriyama, Hiroki Hosoi, Masaya Shimanuku, Toshiki Mushino, Shogo Murata, \\ Akinori Nishikawa, Shinobu Tamura, Nobuyoshi Hanaoka and Takashi Sonoki*
}

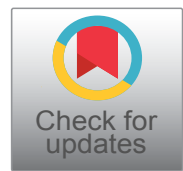

Hematology/Oncology, Wakayama Medical University, Japan

*Corresponding author: Takashi Sonoki, M.D. Ph.D, Hematology/Oncology, Wakayama Medical University, 811-1 Kimi-idera, Wakayama 641-8510, Japan

\begin{abstract}
Background: In previous studies, it has been reported that $10-20 \%$ of acute myeloid leukemia (AML) cases showed immunoglobulin heavy chain gene $(I G H)$ rearrangements, a genetic hallmark of B-cell differentiation. However, the clinical significance of this is uncertain. Here, we report a case of diffuse large B-cell lymphoma (DLBCL) after complete remission (CR) from AML that exhibited an $I G H$ rearrangement.
\end{abstract}

Case presentation: The patient was diagnosed with AML (M4Eo) with inversion of chromosome 16 [inv(16)]. Interestingly, the AML cells showed a monoallelic IGH rearrangement, as detected by the Southern blot analysis. The rearranged band was cloned using the inverse polymerase chain reaction (PCR) method. The sequence result revealed that a recombination between $\mathrm{DH} 7-27$ and $\mathrm{JH} 4$ occurred in the AML cells. PCR using DH7-27and $\mathrm{JH} 4$-specific primers yielded no band from DLBCL specimens, suggesting that the DLBCL did not occur owing to the AML cell with $I G H$ rearrangement. In addition, fluorescent in situ hybridization (FISH) showed that inv(16) was not found in the DLBCL cells. Therefore, although the AML cells harbored an $I G H$ rearrangement, the origins of the two tumors seemed to differ from each other.

Conclusion: As the prognosis of AML became better, longterm follow-up studies of AML patients might define the clinical significance of $I G H$ rearrangements in AML cells.

\section{Keywords}

Acute myelogenous leukemia (M4Eo), Diffuse large B-Cell lymphoma, $I G H$ rearrangement

\section{Introduction}

Immunoglobulin heavy chain gene (IGH) rearrangement is a genetic hallmark of B-cell origin and differentiation [1-3]. However, it has been demonstrated in previous reports that IGH rearrangements were also found in approximately $10-20 \%$ of patients with acute myeloid leukemia (AML) [4-11]. However, the clinical characteristics of AML with IGH rearrangements remain to be identified.

AML after lymphoid malignancies is well described as therapy-related AML or myelodysplastic syndrome (MDS) $[12,13]$. These secondary myeloid malignancies are thought to be due to genetic mutations induced by chemotherapies or radiotherapies. However, the occurrence of diffuse large B-cell lymphoma (DLBCL) after myeloid neoplasms is not well described in the literature.

Here, we describe a rare case of DLBCL that occurred after complete remission (CR) of AML with inversion of chromosome 16 [inv(16)] (M4Eo). Interestingly, the AML cells exhibited $I G H$ rearrangements, suggesting differentiation toward B-cells. Thus, the origin of the patient's AML an DLBCL cells was analyzed using IGH rearrangement and inv(16) as genetic markers.

\section{Case Description}

\section{Clinical records}

A 54-year-old man was admitted to our hospital

Citation: Kuriyama K, Hosoi H, Shimanuku M, Mushino T, Murata S, et al. (2019) Diffuse Large B-Cell Lymphoma during Complete Remission of Acute Myeloid Leukemia (M4Eo) Exhibiting Immunoglobulin Heavy Chain Gene Rearrangement and Inv(16). Int J Blood Res Disord 6:036. doi. org/10.23937/2469-5696/1410036

Accepted: January 23, 2019: Published: January 25, 2019

Copyright: (c) 2019 Kuriyama K, et al. This is an open-access article distributed under the terms of the Creative Commons Attribution License, which permits unrestricted use, distribution, and reproduction in any medium, provided the original author and source are credited. 
complaining from fever and dyspnea. There was no family history suggesting familial cancer syndromes or germline DNA repair mutations. Laboratory test results revealed anemia (hemoglobin: $8.5 \mathrm{~g} / \mathrm{dL}$; reference range: 13.5-17.5 g/dL), thrombocytopenia (platelet count: 4.5 $\times 10^{9} / \mathrm{L}$; reference range: $130-370 \times 10^{9} / \mathrm{L}$ ), and elevated white blood cell count $\left(11.9 \times 10^{9} / \mathrm{L}\right.$; reference range: $3.5-9.8 \times 10^{9} / \mathrm{L}$ ) with $27 \%$ blasts. Bone marrow aspiration revealed a markedly variable number of immature monocytes and eosinocytes (Figure 1A). Leukemic cells were positive for $\mathrm{CD} 13, \mathrm{CD} 33, \mathrm{CD} 34$, and HLA-DR; and negative for CD19, CD7, and CD3 as measured by flow-cemetery. Inv(16) was detected using fluorescent in situ hybridization (FISH) (Figure 1B). Conventional karyotyping confirmed the inv(16) (data not shown). Based on the results, the patient was diagnosed with AML with eosinophilia (M4Eo). He achieved CR with conventional chemotherapy (induction chemotherapy and four courses of consolidation chemotherapy with anthracyclines and cytarabine). Then, he was followed up without maintenance chemotherapy at the outpatient clinic of our hospital.

Three years after the diagnosis of AML, he presented at the emergency department of our hospital complaining of severe abdominal pain. He was diagnosed with peritonitis due to perforation of the ileocecal tumor (Figure 1C). The pathological findings of the ileocecal tumor revealed diffuse proliferation of the oval large lymphoid cells (Figure 1D). In addition, immuno histochemical staining demonstrated that the tumor cells were positive for CD10 and CD20 and negative for CD5, CD15, CD30, CD34, CD56, and cyclin D1. The tumor was diagnosed as DLBCL. He received four cycles of R-ACES regimen (Rituximab; $375 \mathrm{mg} / \mathrm{m}^{2}$ day1, Carboplatin; $100 \mathrm{mg} / \mathrm{m}^{2}$ day 2-5, Etoposide; 80 $\mathrm{mg} / \mathrm{m}^{2}$ day2-5, methylprednisolone; $500 \mathrm{mg} /$ body day26, Cytarabine; $2000 \mathrm{mg} / \mathrm{m}^{2}$ day6) for induction therapy. Then, he received R-MEAM regimen (Rituximab; $375 \mathrm{mg} / \mathrm{m}^{2}$ day-7, Ranimusutine; $250 \mathrm{mg} / \mathrm{m}^{2}$ day-7, Cytarabine; $400 \mathrm{mg} / \mathrm{m}^{2}$ day-6-3, Etoposide; $200 \mathrm{mg} /$ $\mathrm{m}^{2}$ day-6-3, Melphalan; $140 \mathrm{mg} / \mathrm{m}^{2}$ day-2) as high dose chemotherapy followed by autologous peripheral blood stem-cell transplantation. He achieved CR, and then he was followed up at the outpatient clinic of our hospital without AML or DLBCL relapse.

\section{Materials and Methods}

\section{Southern blot analysis of the IGH region}

Genomic DNA of the bone marrow cells in AML (M4Eo) at diagnosis was digested by Pstl or Hindlll. After electrophoresis in $0.8 \%$ agarose gel and $1 \times \mathrm{TAE}$ buffer, the digested DNA was transferred onto a nylon membrane (Roche, Mannheim, Germany). A DNA fragment of the $I G H$ joining region was labeled with digoxi-
A
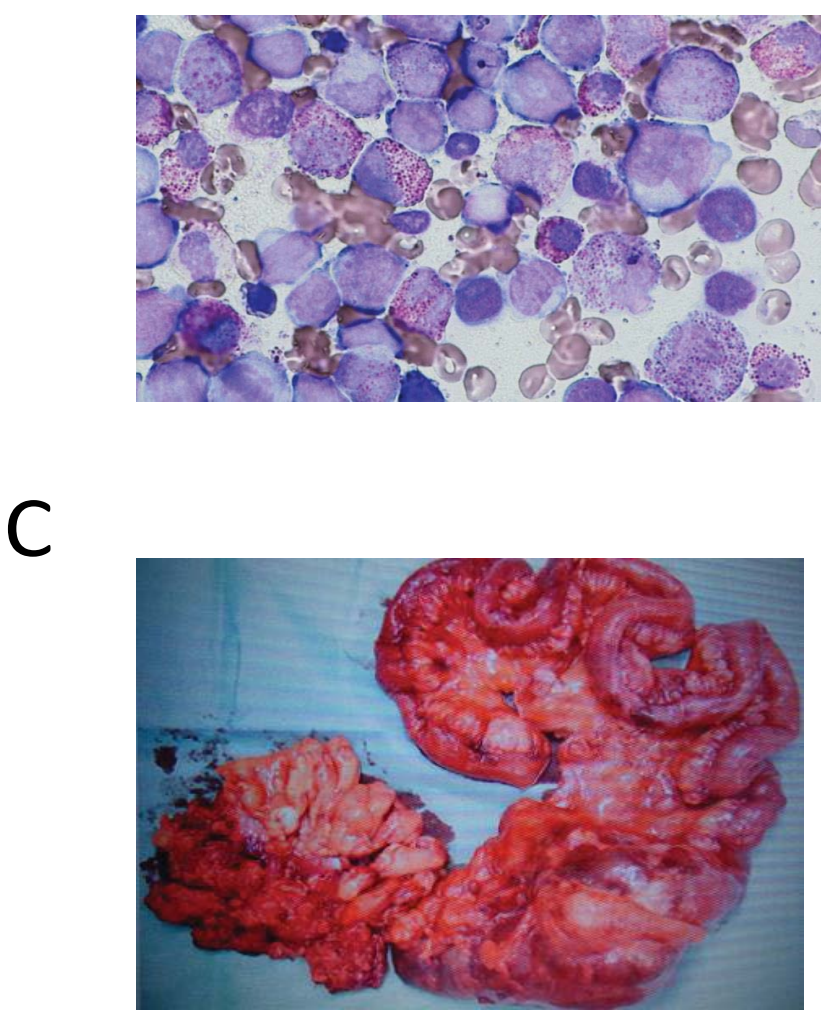
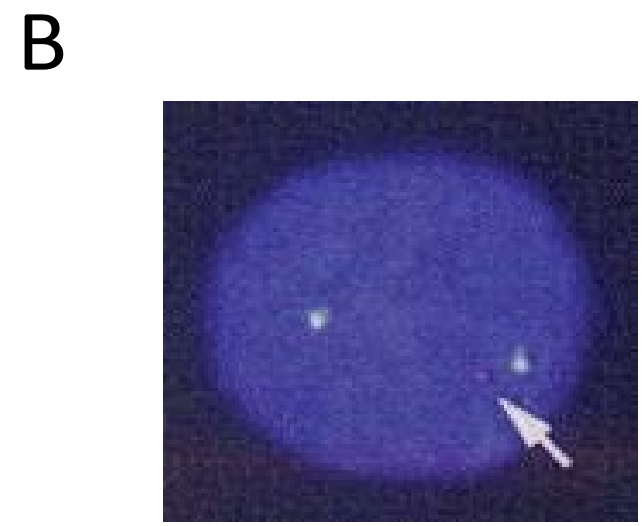

D

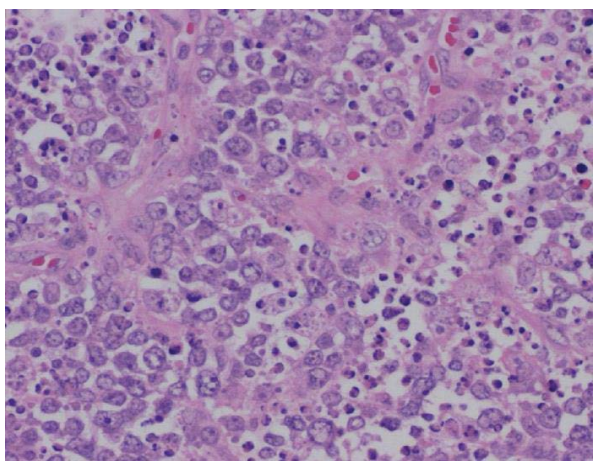

Figure 1: A) Bone marrow smear showing the proliferation of the blast, immature monocyte, and eosinocytes (MayGrünwald Giemsa staining, $\times 200$ ); B) Interphase FISH for the CBF $\beta$ locus showing a split signal (arrow), indicating an inversion or translocation involving the occurrence of CBF $\beta$; C) Resected ileocecal tumor; D) lleocecal tumor showing diffuse proliferation of oval large lymphoid cells, which is consistent with DLBCL (hematoxylin and eosin staining, $\times 400$ ). 
genin using a DIG-DNA labeling kit (Roche) and used as a probe according to the manufacturer's protocol. Hybridization, washing, and detection were also performed according to the manufacturer's protocols (Roche).

\section{Cloning of IGH rearranged band through inverse Polymerase Chain Reaction (PCR)}

In order to determine the nucleotide alignment of the IGH rearranged band seen in Southern blot analysis, inverse PCR was performed to clone the rearranged band using stocked genomic DNA obtained at the onset of AML(M4Eo), as reported elsewhere [14]. Briefly, 1 $\mathrm{gg}$ of genomic DNA of the AML cells was digested by PstI completely. The aliquot of $10 \mathrm{ng} / \mathrm{mL}$ of digested DNA was reacted with T4 ligase at $4{ }^{\circ} \mathrm{C}$ for $16 \mathrm{~h}$, in order to generate self-ligated circular DNA. The circular DNA was then subjected to nested PCR using LA-Taq polymerase (Takara, Shiga, Japan). After electrophoresis, the PCR product of interest was isolated using a gel extraction kit (QIAGEN, Hilden, Germany). The nucleotide alignment of the PCR product was determined directly using Sanger's method.

\section{Detecting the unique sequence of the rearranged IGH through PCR}

The forward (5'-TGAGCTGAGAACCACTGTGC-3') and reverse (5'-AGGAGACCCAGCACCCTTAT-3') primers were set at $5^{\prime}$-upstream $\mathrm{DH}$ and $3^{\prime}$-downstream $\mathrm{JH} 4$, respectively. The estimated PCR products of IGH rearrangement of AML (M4Eo) and germ line of control cells were calculated as $177 \mathrm{bp}$ and 1,448 bp, respectively. The genomic DNA of the DLBCL was extracted from a paraffin-embedded tissue piece according to the manufacturer's protocol by TaKaRa DEXPAT (Takara, Kyoto Japan). PCR was performed on the patient's DLBCL and AML cells using the primers.

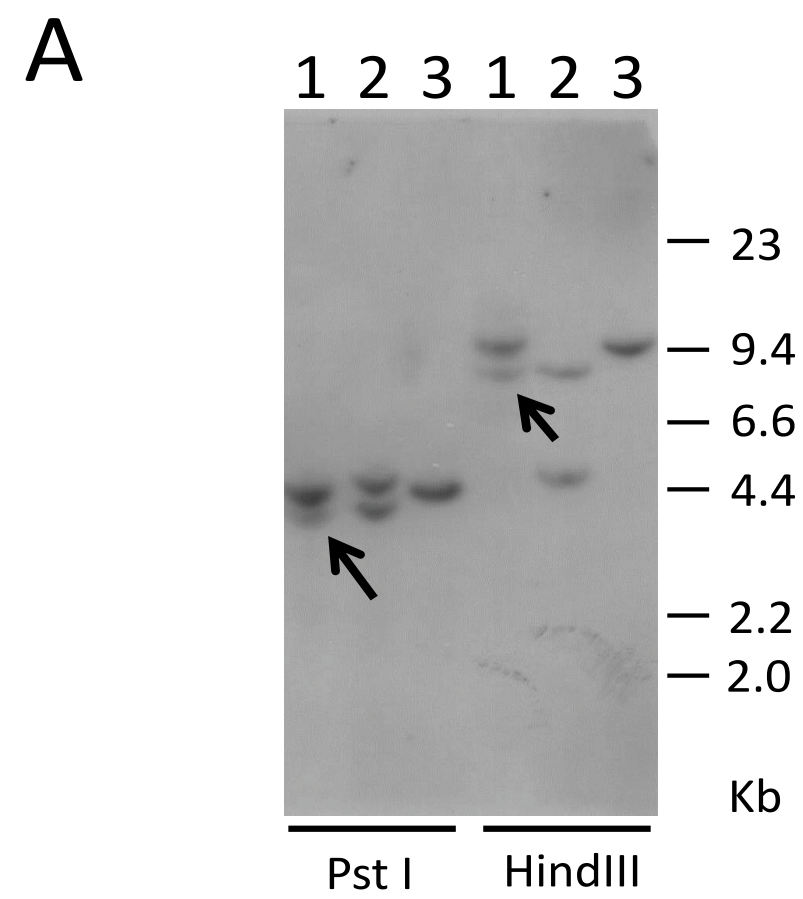

B
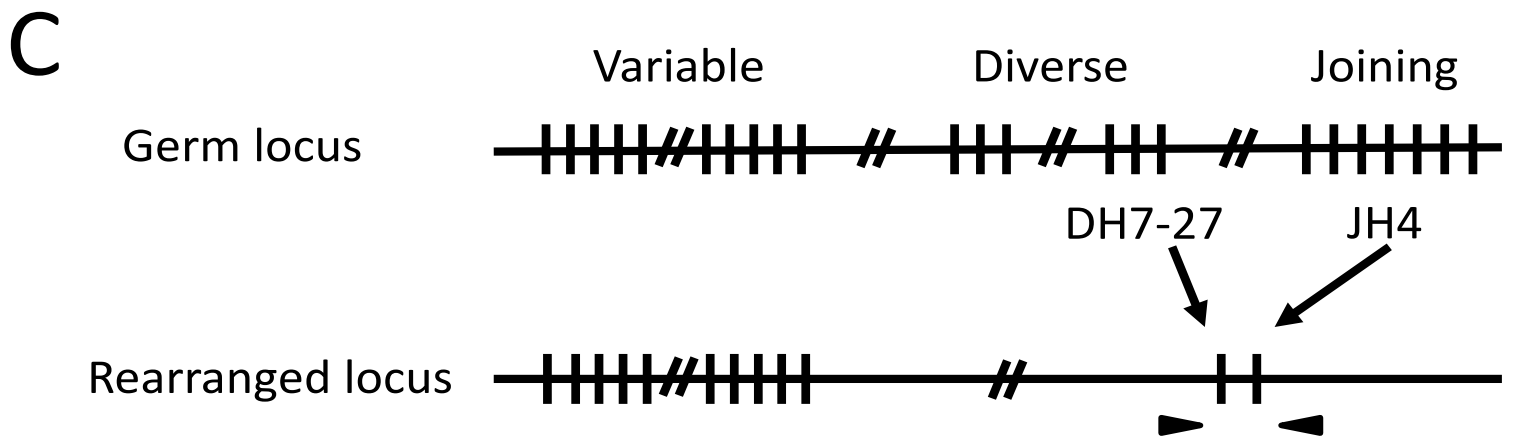

Figure 2: A) Southern blot analysis of the $I G H-J H$ region. Line 1: Bone marrow cells obtained at AML diagnosis (M4Eo). Line 2: Positive control (B-cell lymphoma cell line, KHM2B). Line 3: Negative control (myeloid tumor cell line, HL60). The arrows indicate rearranged bands. All DNA was digested by Pstl or HindIII; B) Molecular cloning of the rearranged IGH$J H$ region by inverse PCR using self-ligated circular DNA after Pstl digestion as a template. M: DNA marker $(\lambda / H i n d l I I+\varphi /$ HaellI); Pt: Bone marrow cells obtained at AML diagnosis (M4Eo). The upper and lower arrows indicate germ line (G) and rearranged $(\mathrm{R})$ bands, respectively; C) AML (M4Eo) cells showing a recombination between $\mathrm{DH} 7-27$ and JH4. The arrowheads represent primers amplifying the recombination DNA. 


\section{Detection of inv(16) on AML and DLBCL cells using FISH}

FISH was performed on the interphase nuclei using CBF $\beta$ split probes set at $5^{\prime}$ and $3^{\prime}$ of the CBF $\beta$ locus. When an inversion or translocation occurred around the $\mathrm{CBF} \beta$ locus, the probes showed a split signal. FISH was performed at another institute (BML, Kawagoe, Japan).

\section{Results}

\section{Molecular analyses of the IGH region of AML (M4Eo) cells}

Possible IGH rearrangements in the AML (M4Eo) cells before the onset of DLBCL were assessed. Interestingly, the Southern blot analysis of the AML cells showed a monoallelic $I G H$ rearranged band (Figure $2 \mathrm{~A}$ ) in various endonuclease digestions. The $2.4 \mathrm{~kb}$ rearranged band found in Pstl digestion was amplified and cloned using inverse-PCR (Figure 2B). The nucleotide alignment of the PCR product revealed that the AML cells underwent recombination between DH7-27 and JH4 (Figure 2C).

\section{PCR analysis of the DLBCL cells using the DH7-27 and JH4 primers}

Furthermore, whether the clonal IGH rearrangement of the AML cells was found in the DLBCL cells was assessed. We prepared specific primers that can amplify the recombined sequence (DH7-27 and $\mathrm{JH} 4$ ) of the rearranged IGH locus of the AML cells. The expected band (177 bp) was detected in AML (M4Eo); however, PCR of this patient's DLBCL cells was performed using the primers, no band was detected (Figure $3 \mathrm{~A}$ ). Thus, this result suggested that $I G H$ rearrangements in DLBCL cells differ from those in AML cells.

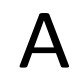

\section{Inv(16) of FISH on DLBCL cells}

$\operatorname{Inv}(16)$ in this patient's DLBCL cells was analyzed using FISH. The DLBCL cells showed no split signal, indicating that they did not harbor inv(16) (Figure 3B).

\section{Conclusions}

Here, we reported a patient who developed secondary DLBCL during the CR of AML. Interestingly, the AML cells harbored an IGH rearrangement and inv(16). Therefore, the tumor origins of AML and DLBCL were examined by genetic analyses. As a result, the origins were found to be different from each other in terms of IGH rearrangement and inv(16). However, we did not rule out that some other genomic mutations might be predisposed to the development of the both hematological malignancies.

Myeloid malignancies after chemotherapy or radiotherapy are well known as therapy-related AML or MDS $[12,13]$. However, secondary lymphoid tumors following AML are rare. Higuchi, et al. reported EpsteinBarr virus-positive DLBCL during CR of AML [15]. In this case, the rearrangement patterns of the $I G H$ in the two malignancies were different. However, they showed that these two malignancies had a common clonal origin, indicated by chromosomal translocation $t(3 ; 4)(p 25 ; q 21)$; therefore, they concluded that the tumors possibly had common origins. In our case, the tumor origins of AML and DLBCL cells were found to be different from each other, according to the genetic analyses of IGH rearrangement and inv(16).

It has been shown in previous reports that AML exhibited an IGH gene rearrangement in approximately $10-20 \%$ of all cases. However, the clinical features of AML with $I G H$ rearrangement are still unidentified.

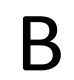

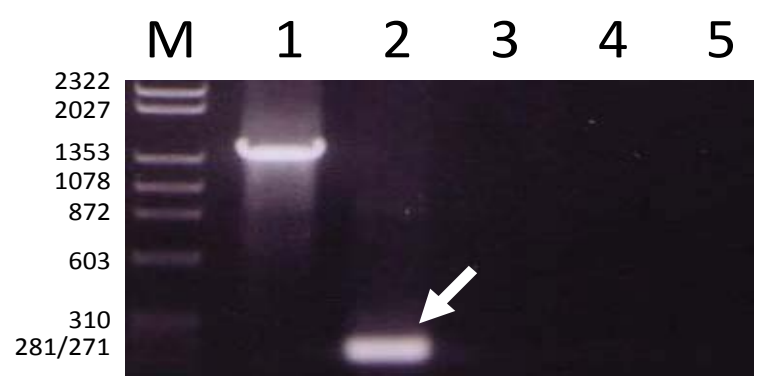

(bp)

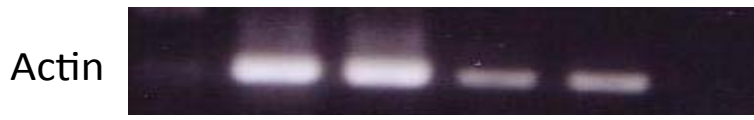

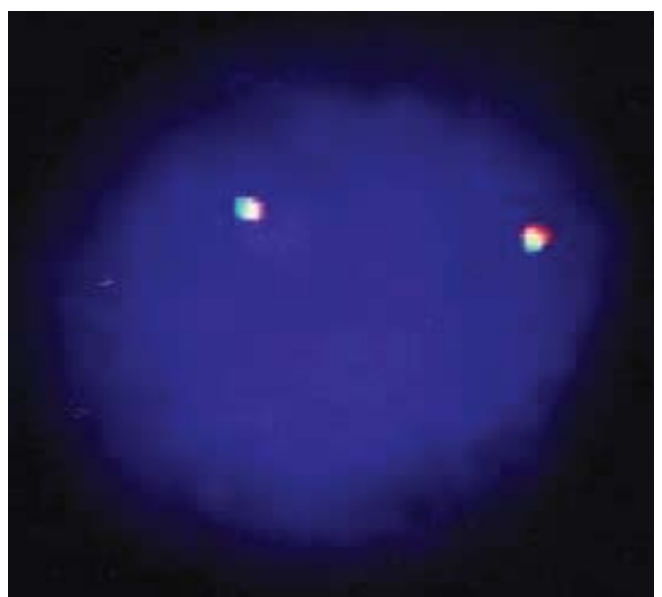

Figure 3: A) 1,448 bp DNA representing the DH/JH4 germ line amplified in the germ line control DNA (lane 1). A 177 bp $\mathrm{DH} / \mathrm{JH} 4$ recombination fragment amplified in the AML (M4Eo) sample (lane 2, arrow). Lane 1: HL60 (germ line control). Lane 2: AML DNA (M4Eo). Lanes 3 and 4: DLBCL DNA. Lane 5: Negative control $\left(\mathrm{H}_{2} \mathrm{O}\right)$; B) FISH for inv(16) in DLBCL cells showing no split signal. 
Kyoda, et al. reported that IGH-rearrangements of AML may be considered as a poor prognostic factor of $C R$ and survival [6]. However, it has been shown in other reports that IGH rearrangement of AML did not affect the prognosis [7]. These differences may be due to the short observation period. Recently, there has been an improvement in the survival of patients with AML [16]. Therefore, the characteristics and clinical features of AML with IGH rearrangement might become clear in a long-term observation period.

In conclusion, we reported a rare case of DLBCL that developed during the CR of AML with IGH rearrangement and inv(16). Since $I G H$ rearrangements due to clonal B cell proliferation can be found among older persons, IGH rearrangements might be just coincidence in AML. Further studies are required to determine the clinical significance of $I G H$ rearrangements in AML.

\section{Conflict of Interest}

All authors declare to have no conflicts of interest in this work.

\section{References}

1. Trainor KJ, Brisco MJ, Story CJ, Morley AA (1990) Monoclonality in B-lymphoproliferative disorders detected at the DNA level. Blood 75: 2220-2222.

2. Trainor KJ, Brisco MJ, Wan JH, Neoh S, Grist S, et al (1991) Gene rearrangement in B- and T-lymphoproliferative disease detected by the polymerase chain reaction. Blood 78: 192-196.

3. Sandberg $\mathrm{Y}$, van Gastel-Mol EJ, Verhaaf $\mathrm{B}$, Lam $\mathrm{KH}$, van Dongen JJ, et al. (2005) BIOMED-2 multiplex immunoglobulin/T-cell receptor polymerase chain reaction protocols can reliably replace Southern blot analysis in routine clonality diagnostics. J Mol Diagn 7: 495-503.

4. Oster W, Konig K, Ludwig WD, Ganser A, Lindemann A, et al. (1988) Incidence of lineage promiscuity in acute myeloblastic leukemia: Diagnostic implications of immunoglobulin and T-cell receptor gene rearrangement analysis and immunological phenotyping. Leuk Res 12: 887-895.

5. Adriaansen $\mathrm{HJ}$, Soeting $\mathrm{PW}$, Wolvers-Tettero IL, van Dongen JJ (1991) Immunoglobulin and T-cell receptor gene rearrangements in acute non-lymphocytic leukemias. Analysis of 54 cases and a review of the literature. Leukemia 5: 744-751.

6. Kyoda K, Nakamura S, Matano S, Ohtake S, Matsuda $T$ (1997) Prognostic significance of immunoglobulin heavy chain gene rearrangement in patients with acute myelogenous leukemia. Leukemia 11: 803-806.

7. Yen CC, Liu JH, Wang WS, Chiou TJ, Fan FS, et al. (1999) Prognostic significance of immunoglobulin and $T$ cell receptor gene rearrangements in patients with acute myeloid leukemia: Taiwan experience. Leuk Lymphoma 35: 179-187.

8. Schmetzer HM, Braun S, Wiesner D, Duell T, Gerhartz HH, et al. (2000) Gene rearrangements in bone marrow cells of patients with acute myelogenous leukemia. Acta Haematol 103: $125-134$.

9. Boeckx N, Willemse MJ, Szczepanski T, van der Velden $\mathrm{VH}$, Langerak AW, et al. (2002) Fusion gene transcripts and Ig/TCR gene rearrangements are complementary but infrequent targets for PCR-based detection of minimal residual disease in acute myeloid leukemia. Leukemia 16: 368-375.

10. Stavroyianni N, Belessi C, Stamatopoulos K, Kosmas C, Paterakis G, et al. (2003) Expression of recombination activating genes- 1 and- 2 immunoglobulin heavy chain gene rearrangements in acute myeloid leukemia: Evaluation of biological and clinical significance in a series of 76 uniformly treated patients and review of the literature. Haematologica 88: $268-274$.

11. Noor Haslina MN, Marini R, Rosnah B, Shafini MY, Wan Haslindawani WM, et al. (2013) immunoglobulin heavy chain gene rearrangement in non B-cell haematological malignancies. West Indian Med J 62: 701-704.

12. Steinberg MH, Geary CG, Crosby WH (1970) Acute granulocytic leukemia complicating Hodgkin's disease. Arch Intern Med 125: 496-498.

13. Arber DA, Orazi A, Hasserjian R, Thiele J, Borowitz MJ, et al. (2016) The 2016 revision to the World Health Organization classification of myeloid neoplasms and acute leukemia. Blood 127: 2391-2405.

14. Akasaka T, Balasas T, Russell LJ, Sugimoto KJ, Majid A, et al. (2007) Five members of the CEBP transcription factor family are targeted by recurrent IGH translocations in B-cell precursor acute lymphoblastic leukemia(BCP-ALL). Blood 109: 3451-3461.

15. Higuchi M, Sasaki S, Kawadoko S, Uchiyama H, Yasui T, et al. (2015) Epstein-Barr virus-positive diffuse large B-cell lymphoma following acute myeloid leukemia: A common clonal origin indicated by chromosomal translocation $\mathrm{t}(3 ; 4)$ (p25;q21). Int J Hematol 102: 482-487.

16. Koreth J, Schlenk R, Kopecky KJ, Honda S, Sierra J, et al. (2009) Allogeneic stem cell transplantation for acute myeloid leukemia in first complete remission: Systematic review and meta-analysis of prospective clinical trials. JAMA 301: 2349-2361. 